\title{
Effects of rehabilitation on the patients with chronic low back pain
}

\author{
M. A. Shakoor, M. Tariqul Islam, A. K. M. Salek and Md. Moyeenuzzaman
}

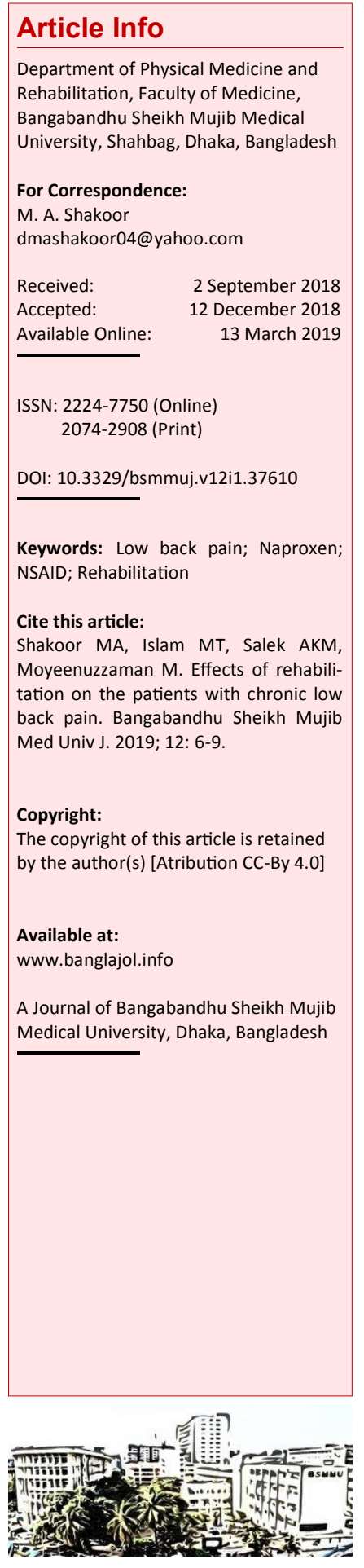

\section{Abstract}

This study was done to observe the effects of rehabilitation on chronic low back pain on 139 patient. They were divided into two groups: a) One group $(n=71)$ received naproxen (nonsteroidal anti-inflammatory drug, NSAID) with selective rehabilitation and $b$ ) another group $(n=$ 68) treated with NSAID only. The patients were followed up weekly for eight weeks. The improvement was found in both groups after treatment. In patients with rehabilitation, the pretreatment and post-treatment mean scores (Oswastry Disability Index, Visual Analogue Scale and Modified Zung Index) were $34.3 \pm 9.8$ and $9.9 \pm 8.0$ respectively $(p<0.001)$. Treatment with NSAID only reduced the mean scores from $34.9 \pm 13.5$ to $16.0 \pm 14.4(\mathrm{p}<0.001)$ after treatment. There was no significant difference in clinical improvement between the groups in pre-treatment compare with week one, rehabilitation group $(29.7 \pm 8.7)$ vs NSAID group $(31.5 \pm 13.8)$. While significant improvement was found in rehabilitation group in comparison to NSAID group after 8th week, rehabilitation group vs NSAID group scores were $10.0 \pm 7.9$ vs $15.9 \pm 14.5$ respectively $(p=0.004)$. In conclusion, rehabilitation can be used as an adjunct to NSAID for better improvement.

\section{Introduction}

Low back pain is a self-limiting symptom which affects the area between the lower border of the 12th rib and gluteal folds and usually radiates to the lower limb. 1 It becomes chronic when it lasts more than three months.? It remains less understood and insufficiently treated because of the heterogeneity of the patients, and difficult to apply for patients clinically. $\underline{3}$ Chronic low back pain is the leading cause of limited activity in people under the age of 45 years. $\underline{4}$

There are many options of treatment. Chronic pain needs multidisciplinary rehabilitation program to manage it effectively having multiple inter-relating social, occupational, physical and psychological factors. 5 Moore et al. (2000) stated disability due to low back pain has increased in the past 20 years and is usually due to psychological and social factors. 6 A study showed that low back pain is the single most common musculoskeletal condition and the main cause for being out of duty from the job, resulting in huge loss of wages per year.? Many patients of low back pain become chronic and it is about $5-10 \%$. Limitation of activity due to low back problems are the most frequently found in persons aged less than 45 years. 9 Financial compensation and social security disability benefits is received by $17.3 \%$ of low back pain patients. 10 Both conservative and surgical option of treatment is available for the treatment of chronic low back pain. It was found that surgery is always not necessary in persistent back pain, but surgery may be necessary when there is a major neurological deficit. But in prolapse disc, spondylolisthesis or spinal stenosis usually do not need surgery. $\underline{\underline{11}}$ This study was conducted to find out the effects of rehabilitation measure to improve the disability of the patient with chronic low back pain.

\section{Materials and Methods}

This study was conducted from July 2010 to June 2011. On arrival of the patients, history, physical examination and investigations were done. The subjects were selected according to the inclusion criteria: a) Subjects were included irrespective of sex, b) age (30-70 years), c) low back pain for $>3$ months, d) low back pain due to any chronic cause and e) no evidence of malignancy or skin infection.

About 170 patients were selected according to the criteria and divided into two groups randomly by the way of lottery manually: a) Rehabilitation group $(\mathrm{n}=85)$ : subjects were treated with selective rehabilitation treatment with non-steroidal anti-inflammatory drug (NSAID) whereas b) non-rehabilitation group $(n=85)$ : subjects were treated with NSAID only.

Among the NSAIDs, naproxen $(250 \mathrm{mg}$ ) was given to the subjects twice daily orally. Tablet 
Table I

Baseline clinical criteria of the patients with low back pain

\begin{tabular}{|c|c|c|c|c|c|c|c|c|}
\hline Group & $\mathrm{n}$ & $\begin{array}{r}\text { Age } \\
\text { (years) }\end{array}$ & $\begin{array}{r}\text { Height } \\
(\mathrm{cm})\end{array}$ & $\begin{array}{r}\text { Weight } \\
(\mathrm{kg})\end{array}$ & $\begin{array}{r}\text { SBP } \\
(\mathrm{mm} \mathrm{Hg})\end{array}$ & $\begin{array}{r}\mathrm{DBP} \\
(\mathrm{mmHg})\end{array}$ & $\begin{array}{r}\text { ESR after 1st } \\
\text { hour (mm) }\end{array}$ & $\begin{array}{l}\text { Blood sugar } \\
\text { (2HPPBS in mmol/L) }\end{array}$ \\
\hline Rehabilitation & 71 & $42.8 \pm 9.2$ & $155.6 \pm 8.5$ & $57.7 \pm 9.2$ & $124.3 \pm 13.6$ & $76.4 \pm 8.2$ & $22.7 \pm 13.6$ & $6.3 \pm 1.9$ \\
\hline Non-rehabilitation & 68 & $42.9 \pm 9.4$ & $16.0 \pm 7.1$ & $57.0 \pm 8.4$ & $122.5 \pm 13.9$ & $75.5 \pm 8.2$ & $25.6 \pm 15.8$ & $5.9 \pm 1.0$ \\
\hline$p$ value & & 0.91 & 0.99 & 0.61 & 0.43 & 0.52 & 0.23 & 0.13 \\
\hline
\end{tabular}

naproxen was purchased from a local company and distributed to the patient weekly. The adherence of the patient was assessed by counseling.

\section{Rehabilitation measurements}

Activity modification in the form of activities of daily living instructions was given to protect the back in the rehabilitation group. The instructions were given in local language with pictures to the patients to maintain right posture and to protect the back from microinjury. Walking aids, lumber corset, high commode, foot rest etc. were prescribed in the rehabilitation group only. Exercise in the form of back muscle extension strengthening exercise, back muscle flexion exercise (in case of hyperlordotic patients) and pelvic tilting exercise were prescribed in the rehabilitation group.

\section{Procedure of data collection}

At the time of first attendance, patients were assessed properly by the assessment tools and it was recorded. The patients were followed-up weekly for eight weeks. Oswastry Disability Index, Visual Analogue Scale and Modified Zung Index were used to evaluate the patients for outcome and was recorded in the data schedule. $\underline{\mathbf{1 2}, 13}$ Here, we used summation of these three tools for statistical analysis because all three parameters were numerical and showed improvement when it became increased and when decreased it denotes the worseness of the symptoms.

\section{Statistics}

The numerical data were analyzed statistically by using the SPSS version-21 for Windows. Student's ' $t$ ' test and Chi-squared test were done. Both paired and unpaired ' $t$ ' tests were performed as required to find out a significant level. The results were described as mean \pm standard deviation (SD) unless otherwise stated and $\mathrm{p}<0.05$ was considered as the level of significance.

\section{Results}

Among the 170 patients, 31 were dropped out (14 from the rehabilitation group and 17 from the nonrehabilitation group) because they could not follow the allocated treatment regularly. Ultimately 139 patients (53 males, 86 females) followed the treatment regularly. The baseline characteristics of both groups were more or less similar (Table I).

The patients of the rehabilitation group $(n=71)$ showed significant $(p=0.001$, Figure 1$)$ improvement which started after one week. The improvement gradually increased and at the end of treatment highly significant improvement was found in this group i.e. pre-treatment and post treatment (end of 8 th week), the mean scores were $34.4 \pm 9.9$ and $9.9 \pm$ 8.0 respectively $(\mathrm{p}=0.001)$.

There were 68 patients finally completed the trial in the non-rehabilitation group. Significant improvement was found after treatment. The improvement was started after first week, pre-treatment and at the end of first week, the mean scores were $34.9 \pm$ 13.5 and $31.6 \pm 13.5$ respectively $(p=0.001)$. The improvement gradually increased and at the end of treatment significant improvement was found in this group i.e. pre-treatment and post treatment (end of 8th week), the mean scores were $34.9 \pm 13.5$ and $16.1 \pm 14.5$ respectively ( $\mathrm{p}=0.001$ ). This indicates that NSAID was also effective in chronic low back pain.

The comparison between the two groups shows that there was no difference regarding improvement in pre-treatment compared after week 1. More improvement was found in the rehabilitation group than NSAIDs after 3rd week, rehabilitation group verses NSAIDs group scores were $23.3 \pm 8.5$ vs. 27.5 \pm 13.8 respectively $(p=0.03)$. Then improvement was gradually increased in rehabilitation group than non-rehabilitation group and finally significant improvement was found in rehabilitation group than non-rehabilitation group after 8th week, rehabilitation group vs NSAIDs group, the scores were $10.1 \pm$ 8.0 vs. $16.0 \pm 14.5$ respectively $(p=0.004)$.

\section{Discussion}

There was an improvement after treatment in both the groups in the present study. The improvement of chronic low back pain in both groups appeared after one week. That is, rehabilitation group and NSAIDs groups, both began to improve after star- 


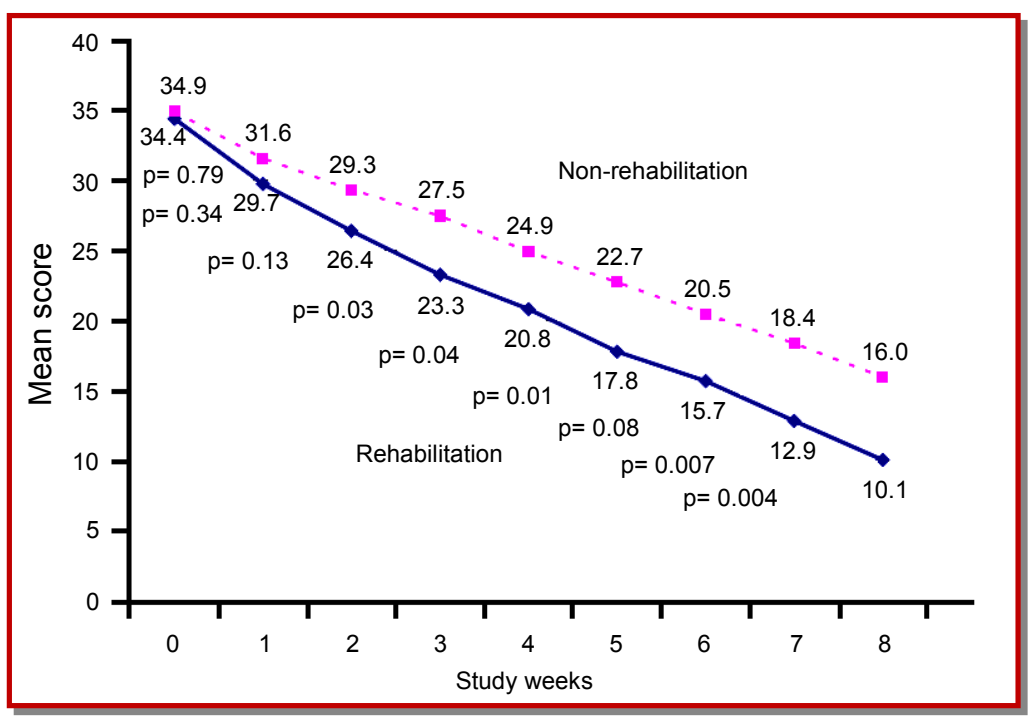

Figure 1: Comparative improvement of symptoms between the groups

ting treatment. But it was not significant statistically. The difference of improvement between two groups was found to begin at the end of 3rd week $(p=0.03)$. The improvement was continued throughout the whole period of the study. And after completion of the treatment i.e. after the end of 8 th week there was a highly significant improvement in both groups. And in comparison, between two groups, a significant improvement of chronic low back pain was found in the patients who received rehabilitation treatment plus NSAID.

Shakoor et al. (2003) found a significant improvement in osteoarthritis of the knee joint using rehabilitation treatment. $\underline{14}$ We used rehabilitation measure in our study on patients having osteoarthritis of lumbar spine and found good improvement. Karthik and Vishwe (2017) found in their study that maximum participants experienced moderate pain at rest whereas it increased to moderate to severe pain with activity and most of them reported their back to be painful almost all of the time and had to change the position frequently to have a comfortable posture without pain. 15 This indicates that posture correction is an important factor to reduce chronic low back pain which is applied in the present study as rehabilitation measure and we found improvement of sumptuous of the patients with chronic low back pain.

Laird et al. (2012) found beneficial effects on low back pain after modifying the pattern of movement.16 We used a modification of activity as a rehabilitation tool and we also found good results. On the other hand, in a review, Chard and Dieppe (2001) found that education, behavioral change, exercise, aids and bracing was moderately effective, and these have no side effects at all in the management of osteoarthritis. .17 Searle et al. (2015) found in their systemic review that strength/resistance and coordination/stabilization exercise programs over other interventions in the treatment of chronic low back pain. $\underline{18}$ Shen et al. (2006) stated that exercises, activity modification and behavioral modification can reduce symptoms in chronic low back pain. $\underline{19} \mathrm{In}$ the present study, we advocated the modification of activity and our patients became benefited. So, activity modifications play important role in the treatment of chronic low back pain. Peul et al. (2007) found in a study that treatment with surgery or conservative measures, the improvement of patients of sciatica was the same after one year.므 Gaskell et al. (2007) and some other clinical finding showed that back rehabilitation program is effective to improve the patients with chronic low back pain. $\underline{21-}$ $\underline{24}$ This study also had some of the rehabilitation measures and found significant improvement of chronic low back pain. This is in favor of the finding of our study. Because we use rehabilitation treatment in the form of activities of daily living instructions to maintain right posture and to protect the back from microinjury, some assistive devices like a high commode, lumbar corset, walking aid, footrest, back muscle exercises and found a significant improvement of chronic low back pain. So, rehabilitation treatment is important and effective treatment for the patients with chronic low back pain and it may be used as an adjunct to NSAID therapy. By which doses of NSAIDs can be reduced if the rehabilitation measure is applied and ultimately side effects of NSAIDs may be reduced.

\section{Conclusion}

Chronic low back pain is improved by NSAIDs but rehabilitation measures may be applied with analgesic for more improvement of the symptoms.

\section{Conflict of Interest}

There is conflict of interest.

\section{Acknowledgement}

We are thankful to Bangladesh Medical Research Council, Mohakhali, Dhaka, Bangladesh for their financial help and ethical approval.

\section{References}

1. Frymoyer JW. Back pain and sciatica. N Engl J Med. 1998; 318: 291-300.

2. Ferreira ML, Ferreira PH, Latimer J, Herbert R, Maher CG. Does spinal manipulative therapy help people with chronic low back pain? Aust J Physiother. 2002; 48: 277-84.

3. BenDebba $\mathrm{M}$, Torgerson WS, Long DM. A vali- 
dated, practical classification procedure for many persistent low back pain patients. Pain 2000; 87: 8997.

4. Khan S, Shamsi S, Abdelkader S. Comparative study of short wave diathermy and exercise together and exercise alone in the management of chronic back pain. Int J Health Sci Res. 2013; 3: 7-13.

5. Guzman J, Esmail R, Karjalainen K, Malmivaara A, Irvin E, Bombardier C. Multidisciplinary rehabilitation for chronic low back pain: Sytematic review. BMJ. 2001; 322: 1511-16.

6. Moore JE, Korf MV, Cherkin D, Saunders K, Lorig K. A randomized trial of a cognitive behavioural program for enhancing back pain self care in a primary care setting. Pain 2000; 88: 145-53.

7. Milhous RL, Hough LD, Frymoyer JW, Ruess JM, Gallagher RM, Wilder DG, Callas PW. Determinants of vocational disability in patients with low back pain. Arch Phys Med Rehabil. 1989; 70: 589-93.

8. Lahad A, Malter AD, Berg AO, Deyo RA. The effectiveness of four interventions for the prevention of low back pain. JAMA. 1994; 272: 1286-91.

9. Deyo RA. Conservative therapy for low back pain: Distinguishing useful from useless therapy. JAMA. 1983; 250: 1057-62

10. Maniadakis N, Gray A. The economic burden of low back pain in the UK. Pain 2000; 84: 95-103.

11. Deyo RA. Back Surgery: Who needs it? N Engl J M. 2007; 356: 2239-43

12. Fairbank JCT, Pynsent PB. The Oswestry disability index. Spine 2000; 25: 2940-53.

13. Williamsa ACC, Davies HTO, Chadury Y. Simple pain rating scales hide complex idiosyncratic meanings. Pain 2000; 85: 457-63.

14. Shakoor MA, Haque MN, Khan AA, Moyeenuzzaman M. Effects of ultrasound therapy (UST) in osteoarthritis of the knee joint. CM-O-S (Child) HJ. 2003; 1: 11-16.

15. Karthik S, Vishwe D. Low back pain: Functional impairments, activity limitations and participation restrictions in farmers. Int J Allied Med Sci Clin Res. 2017; 5: 707-11.

16. Laird RA, Kent P, Keating JL. Modifying patterns of movement in people with low back pain-does it help? A systematic review. BMC Musculoskelet Disord. 2012; 13: 169.

17. Chard J, Dieppe P. The case for nonpharmacologic therapy of osteoarthritis. Curr Rheumatol Rep. 2001; 3: 251-57.

18. Searle A, Spink M, Ho A, Chuter V. Exercise interventions for the treatment of chronic low back pain: A systematic review and meta-analysis of randomised controlled trials. Clin Rehabil. 2015; 29 1155-67.

19. Shen FH, Samartzis D, Andersson GB. Nonsurgical management of acute and chronic low back pain. J Am Acad Orthop Surg. 2006; 14: 477-87.

20. Peul WC, Van Houwelingen HC, van den Hout WB, Brand R, Eekhof JAH, Tans JTJ, Thomeer TWM, Koes BW. Surgery versus prolonged conservative treatment for sciatica. N Engl J Med. 2007; 356: $2245-56$

21. Gaskell L, Enright S, Tyson S. The effects of back rehabilitation programme for patients with chronic LBP. J Eval Clin Pract. 2007; 13: 795-800.

22. Cetin N, Aytar A, Atalay A, Akman MN. Comparing hot pack, short-wave diathermy, ultrasound, and TENS on isokinetic strength, pain, and functional status of women with osteoarthritic knees: A single-blind, randomized, controlled trial. Am J Phys Med Rehabil. 2008; 87: 443-451.

23. Ahmed MS, Shakoor MA, Khan AA. Evaluation of the effects of shortwave diathermy in patients with chronic low back pain. Bangladesh Med Res Counc Bull. 2009; 35: 18-20.

24. Kolu E, Buyukavci R, Akturk S, Eren F, Ersoy Y. Comparison of high-intensity laser therapy and combination of transcutaneous nerve stimulation and ultrasound treatment in patients with chronic lumbar radiculopathy: A randomized single-blind study. Pakistan J Med Sci. 2018; 34: 530-34. 